\title{
Analisis Menu Engineering Hotel Grand Jatra Balikpapan Sebagai Langkah Penetapan Menu Cycle Praktikum Patiseri Program Studi Tata Boga Politeknik Negeri Balikpapan
}

\author{
Yogiana Mulyani, MM. Par. ${ }^{1)}$, Ramli, MM. ${ }^{2)}$, Tuatul Mahfud, S.Pd. M.Pd. ${ }^{3)}$ \\ ${ }^{1}$ Jurusan Tata Boga, Politeknik Negeri Balikpapan \\ email: yogiana.mulyani@poltekba.ac.id \\ ${ }^{2}$ Jurusan Tata Boga, Politeknik Negeri Balikpapan \\ email: admin@poltekba.ac.id \\ ${ }^{3}$ Jurusan Tata Boga, Politeknik Negeri Balikpapan \\ email: tuatul.mahfud@poltekba.ac.id
}

\begin{abstract}
Consistency between the concept of education and training in the academic scope with the human resources quality expected by the industry is extremely important, the industry claims to be able to immediately respond positively to the academic. One of the best is by doing research market demands through menu engineering analysis.

This study was conducted to determine the classification of the patiseri menu at Grand Jatra Hotel Balikpapan. Analysis in study is menu engineering analysis on the menu patiseri, this analysis is used to see the popularity aspects and advantages of the menu items. Then from the results of these studies will be used as recommendations in the preparation of the menu cycle practicum patiseri at Food and Beverage Department State Polytechnic Balikpapan.

The research is a qualitative approach using descriptive analysis with menu engineering analysis methods. Object of this study is patiseri menu at Grand Jatra Balikpapan. Data collection techniques include observation, interviews, documentation, and literature.

The results showed recommendation of menu engineering analysis patiseri at Grand Jatra Balikpapan in the preparation of the menu cycle patiseri in Food and Beverage Department State Polytechnic Balikpapan include 1) Ombre Cake, 2) rainbow cake, 3) fruit cake, 4) brownie cheese cake, 5 ) red velvet cake, 6) opera cake, 7) cheese cake, 8) tiramisu, 9) chocolate harlem, 10) mocha cake, 11) avocado mouse cake, 12) fruit tartalete, 13) blackforest, 14) brownies.
\end{abstract}

Keywords: menu engineering, patiseri, menu cycle

\begin{abstract}
Abstrak
Keselarasan antara konsep pendidikan dan pelatihan (diklat) dalam dunia akademik dengan kualitas SDM yang diharapkan oleh dunia industri sangatlah diperlukan, tuntutan demi tuntutan dunia industri harus dapat segera direspon secara positif oleh dunia akademik. Salah satu upaya tersebut yaitu dengan melakukan penelitian tuntutan permintaan pasar melalui analisa menu engineering.

Penelitian ini dilakukan untuk mengetahui klasifikasi menu patiseri yang ada pada Hotel Grand Jatra Balikpapan. Analisis yang dilakukan adalah menu engineering pada menu patiseri, analisis ini digunakan untuk melihat aspek popularitas dan keuntungan dari item menu. Kemudian dari hasil penelitian tersebut akan digunakan sebagai bahan rekomendasi penyusunan menu cycle dalam praktikum Operasional Patiseri pada Program Studi Tata Boga Politeknik Negeri Balikpapan.

Jenis penelitian ini adalah kualitatif dengan menggunakan analisis deskriptif dengan pendekatan metode analisa menu engineering. Objek penelitian ini yaitu menu patiseri di Hotel Grand Jatra Balikpapan. Teknik pengumpulan data meliputi observasi, wawancara, dokumentasi, dan studi pustaka.

Hasil penelitian menunjukkan rekomendasi dari analisa menu engineering patiseri di Hotel Grand Jatra Balikpapan dalam penetapan menu cycle patiseri di Program Studi Tata Boga Politeknik Negeri Balikpapan yaitu diantaranya 1) Ombre Cake, 2) rainbow cake, 3) fruit cake, 4) brownies cheese cake, 5) red velvet cake, 6) opera cake, 7) cheese cake, 8) tiramisu, 9) chocolate harlem, 10) mocca cake, 11) avocado mouse cake, 12) fruit tartalete, 13) blackforest, 14) brownies.
\end{abstract}

Kata kunci: rekayasa mеnu, patiseri, siklus mепи 


\section{Pendahuluan}

Perkembangan pariwisata saat ini telah mengalami perkembangan yang sangat pesat dan memberikan dampak terhadap pertumbuhan ekonomi dunia. Penelitian yang dilakukan oleh World Tourism Organizatioan (WTO) menunjukkan kecenderungan permintaan terhadap pariwisata akan terus meningkat. Diperkirakan jumlah wisatawan internasional pada tahun 2030 mencapai 1,8 miliar orang (WTO, 2013). Disamping itu, bagi Indonesia sektor pariwisata menempati urutan kelima sebagai penyumbang devisa negara tahun 2012, sektor ini diperkirakan menyumbangkan devisa US\$9,07 miliar pada 2012 (Investor, 2013).

Hal tersebut sejalan dengan amanat yang tertuang pada GBHN tahun 1993 yang memberikan petunjuk bahwa dalam Rencana Pembangunan Lima Tahun Keenam (Repelita VI) pembangunan kepariwisataan terus ditingkatkan dan dikembangkan untuk memperbesar penerimaan devisa, memperluas dan memeratakan kesempatan usaha dan lapangan kerja, mendorong pembangunan daerah, meningkatkan kesejahteraan dan kemakmuran rakyat, memperkaya kebudayaan nasional dengan tetap mempertahankan kepribadian bangsa dan tetap terpeliharanya nilai-nilai agama, mempererat persahabatan antarbangsa, memupuk cinta tanah air, serta memperhatikan kelestarian fungsi dan mutu lingkungan hidup. Pembangunan kepariwisataan juga diarahkan untuk mendorong pengembangan, pengenalan, dan pemasaran produk nasional (Bappenas, 2012).

Kondisi diatas secara tidak langsung juga akan membuka banyak peluang bagi pemenuhan kebutuhan dan perolehan manfaat dari aktivitas pariwisata, terutama di bidang perhotelan. Namun di sisi lain juga melahirkan tantangan dan masalah yang tidak sederhana, tingkat persaingan di bisnis perhotelan pun semakin ketat terutama dalam hal inovasi produk (menu) yang ditawarkan kepada konsumen dan penyiapan Sumber Daya Manusia (SDM) yang unggul. Dalam hal pengembangan produk nasional, pasar wisata global di masa depan menuntut tersedianya produk yang beragam, unik, dan bermutu tinggi (high value production of unique commodities). Hal ini sejalan dengan amanat GBHN tahun 1993 yang mengarahkan untuk dapat mendorong pengembangan, pengenalan, dan pemasaran produk nasional. Disamping itu, dalam hal penyiapan SDM yang unggul dapat pula dilakukan sistem pendidikan dan pelatihan yang memiliki link and match dengan dunia industri. Dalam hal ini Program Studi Tata Boga Politeknik Negeri Balikpapan berupaya untuk menyetarakan kualitas produk dan SDM para mahasiswa dengan tuntutan dunia industri dan pemakai jasa. Disamping menyiapkan sistem pendidikan dan pelatihan SDM yang unggul juga diperlukan kualitas produk praktikum berupa menu cycle praktikum Tata Boga yang sesuai dengan kebutuhan konsumen dan tuntutan industri.

Dalam rangka mendukung Repelita VI dalam pengembangan, pengenalan, dan pemasaran produk nasional, maka diperlukan strategi pengembangan produk nasional di bidang kepariwisataan yaitu salah satunya pengembangan menu cycle praktikum patiseri yang sesuai dengan kebutuhan konsumen atau pelanggan, hal ini dilakukan agar dunia pendidikan dan dunia industri memiliki link and match dalam aspek kebutuhan kompetensi tenaga kerja. Adapun strategi pengembangan menu cycle praktikum patiseri di Program Studi Tata Boga yang dapat dilakukan yaitu analisa menu engineering di Hotel Grand Jatra Balikpapan. Analisa menu engineering tersebut akan dijadikan rekomendasi dalam penyusunan mеnи cycle praktikum patiseri.

\section{Metode Penelitian}

Jenis penelitian ini adalah kualitatif dengan menggunakan analisis deskriptif dengan pendekatan metode analisa menu engineering. Objek penelitian ini yaitu menu patiseri di Hotel Grand Jatra Balikpapan. 
Teknik pengumpulan data meliputi observasi, wawancara, dokumentasi, dan studi pustaka. Data yang didapat dari Hotel Grand Jatra Balikpapan berupa data penjualan menu patiseri selama tiga bulan terakhir yaitu Mei, Juni, dan Juli akan dianalisa secara bertahap dalam proses analisa menu engineering.

\section{Hasil Dan Pembahasan}

Menu engineering adalah pendekatan untuk mengevaluasi harga menu, desain, pengambilan keputusan yang berlaku sekarang dan masa yang akan datang. Selain itu, menu engineering analysis adalah metode untuk mengevaluasi menu dengan tujuan meningkatkan penjualan produk yang paling popular dan menguntungkan.

Sedangkan "Patiseri" merupakan salah satu pengetahuan dalam pengolahan dan penyajian makanan, khususnya mengolah dan menyajikan berbagai jenis kue. Patiseri berasal dari Bahasa Perancis yaitu " Pậtisserie" yang artinya kue-kue. Sehingga dapat disimpulkan bahwa patiseri merupakan ilmu pengetahuan yang mempelajari tentang seluk beluk kue baik kue kontinental, oriental maupun kue Indonesia mulai dari persiapan, pengolahan sampai pada penyajiannya (Faridah, 2008).

Melalui definisi tersebut maka, pengertian menu engineering patiseri merupakan cara untuk mengevaluasi produkproduk patiseri yang populer dan menguntungkan. Sehingga ruang lingkup penelitian yang dibahas meliputi kue kontinental, oriental, dan Indonesia yang diproduksi oleh Hotel Grand Jatra Balikpapan.

Dengan wawasan yang berkembang, saat ini modifikasi kue sangat beragam. Variasi patiseri juga dapat dibentuk dengan berbagai teknik dan metode pengolahan yang berbeda. Namun variasi tersebut tidak dapat dipisahkan dari seni dan keindahan.

Dibawah ini merupakan beberapa produk patiseri Hotel Grand Jatra Balikpapan yang tersedia, yaitu meliputi produk "whole cake" atau cake utuh dan "slice cake" atau cake potong. Rincian produk tersebut yaitu antara lain:

Tabel 1. Menu Display Patiseri Hotel Grand Jatra Balikpapan

\begin{tabular}{|l|l|}
\hline \multicolumn{1}{|c|}{ WHOLE CAKE } & \multicolumn{1}{c|}{ CAKE SLICE } \\
\hline Brownies Cheese Cake $20 \mathrm{~cm}$ & Avocado Mouse cake \\
\hline Red Velvet $20 \mathrm{~cm}$ & Tiramisu \\
\hline Opera cake $24 \mathrm{~cm}$ & Cheese Cake \\
\hline Cheese Cake $20 \mathrm{~cm}$ & Fruit Tartalete \\
\hline Tiramisu $24 \mathrm{~cm}$ & Blackforest \\
\hline Ombre Cake $30 \mathrm{~cm}$ & Red Velvet \\
\hline Blackforest $40 \mathrm{~cm}$ & Hungarian \\
\hline Chocolate Cake $40 \mathrm{x} 60 \mathrm{~cm}$ & Chocolate Merquise \\
\hline Chocolate Harlem $20 \mathrm{x} 20$ & Rainbow \\
\hline Rainbow $40 \mathrm{~cm}$ & Brownies \\
\hline Mocca Cake $24 \mathrm{~cm}$ & Chocolate cake \\
\hline Vanilla Cake $40 \mathrm{~cm}$ & Apple Cramble \\
\hline Fruit Cake $40 \mathrm{~cm}$ & Chocolate harlem \\
\hline Oreo coffee ice cream $24 \mathrm{~cm}$ & Mocca Cake \\
\hline Lapis Surabaya $40 \mathrm{~cm}$ & Opera Cake \\
\hline Hungarian Cake $20 \mathrm{~cm}$ & Brownies Cheese Cake \\
\hline Chocolate Cheese Delight 24 & Key lime \\
\hline
\end{tabular}

\section{Menu Item Analysis}

Analisa ini digunakan untuk mengetahui berapa besar kontribusi setiap satu item menu terhadap keseluruhan menu. Digunakan untuk mendapatkan persentase menu mix (\%МM).

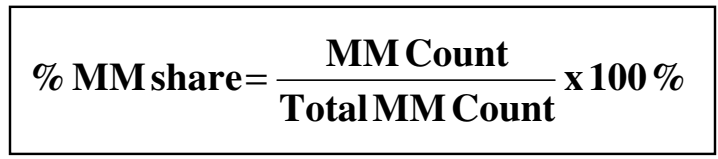

MM Count adalah jumlah makanan yang terjual dari masing-masing menu. Persentase $\mathrm{CM}$ tiap item terhadap total $\mathrm{CM}(\% \mathrm{CM}$ Share), Average CM (ACM).

$$
\% \text { CMShare }=\frac{\text { Item CM } x \text { Item Count }}{\text { Total CM }} \times 100 \%
$$




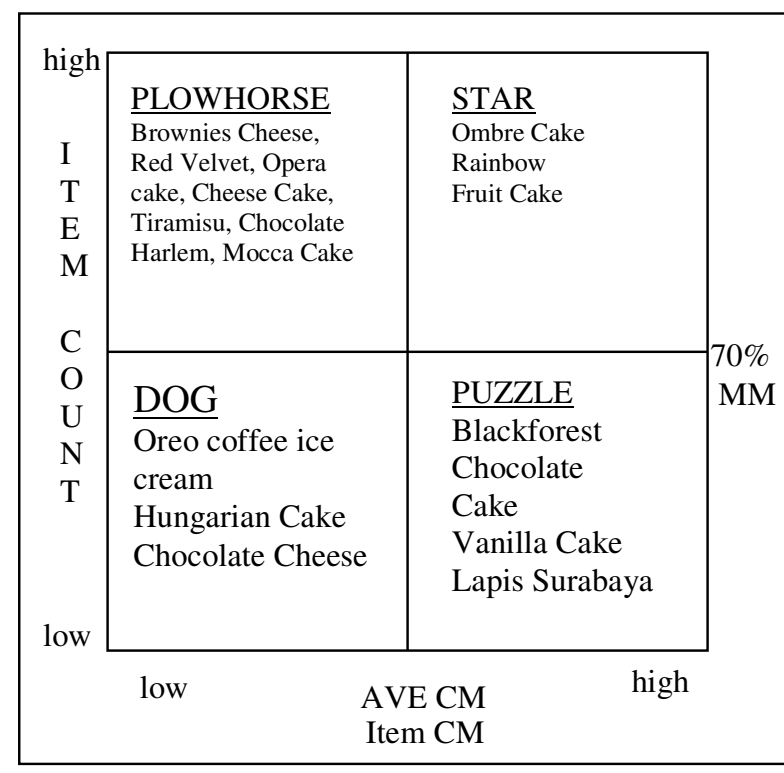

Gambar 1. Summary Four Box Analysis Whole Cake Mei, Juni, Juli 2014

\begin{tabular}{|c|c|c|}
\hline $\begin{array}{c}\text { high } \\
\text { I } \\
\text { T } \\
\text { E } \\
\text { M }\end{array}$ & $\begin{array}{l}\text { PLOWHORSE } \\
\text { Tiramisu, Cheese } \\
\text { Cake, Red Velvet, } \\
\text { Rainbow }\end{array}$ & $\begin{array}{l}\text { STAR } \\
\text { Avocado Mouse } \\
\text { cake, Fruit Tartalete, } \\
\text { Blackforest, } \\
\text { Brownies, Chocolate } \\
\text { harlem, Opera Cake }\end{array}$ \\
\hline $\begin{array}{l}\mathrm{C} \\
\mathrm{O} \\
\mathrm{U} \\
\mathrm{N} \\
\mathrm{T}\end{array}$ & $\begin{array}{l}\underline{\text { DOG }} \\
\text { Brownies Cheese } \\
\text { Cake } \\
\text { Key lime }\end{array}$ & $\begin{array}{l}\text { PUZZLE } \\
\text { Hungarian, Chocolate } \\
\text { Merquise, Chocolate } \\
\text { cake, Apple Cramble, } \\
\text { Mocca Cake }\end{array}$ \\
\hline low & low & high \\
\hline
\end{tabular}

Gambar 2. Summary Four Box Analysis Slice Cake Mei, Juni, Juli 2014

Berdasarkan summary menu mix analysis dan four box analysis whole cake, maka didapatkan beberapa hasil analisa pada kategori menu patiseri whole cake, diantaranya: 1) menu dalam kategori Star yaitu ombre cake, rainbow cake, dan fruit cake; 2) menu dalam kategori Plowhorse yaitu brownies cheese cake, red velvet, opera cake, cheese cake, tiramisu, chocolate harlem, mocca cake; 3) menu dalam kategori Puzzle yaitu black forest, chocolate cake, vanilla cake, lapis surabaya; 4) menu dalam kategori Dog yaitu oreo coffee ice cream, hungarian cake, dan chocolate cheese delight.

Sedangkan hasil summary menu mix analysis dan four box analysis slice cake yaitu 1) menu dalam kategori Star yaitu avocado mouse cake, fruit tartalete, black forest, brownies, chocolate harlem, opera cake; 2) menu dalam kategori Plowhorse yaitu tiramisu, cheese cake, red velvet, rainbow; 3) menu dalam kategori Puzzle yaitu hungarian, chocolate merquise, chocolate cake, apple cramble, mocca cake; 4) menu dalam kategori Dog yaitu brownies cheese cake dan key lime.

Interprestasi data menu dalam kategori Star bermakna menu tersebut merupakan menu yang paling menguntungkan dan paling populer. Menu ini harus dipertahankan kualitas, porsi dan penampilannya. Menu ini sebisa mungkin ditunjukkan secara jelas di menu dan menjadi menu unggulan. Menu makanan dapat dikategorikan star apabila contribution margin mеnu tersebut lebih tinggi daripada average contribution margin dan menu mix percentage-nya lebih besar atau sama dengan popularity index.

Disamping itu, menu dalam kategori Plowhorse berarti menu ini merupakan menu yang populer tapi tidak memberikan keuntungan yang besar. Biasanya merupakan menu yang dipilih oleh pelanggan yang peduli terhadap harga menu. Sebuah menu dapat dikategorikan sebagai plowhorse apabila menu mix percentage-nya lebih besar atau sama dengan popularity index dan contribution margin menu tersebut lebih rendah daripada average contribution marginnya.

Menu dalam kategori Puzzle berarti menu tersebut tidak populer tapi dapat memberikan keuntungan yang cukup besar. Manajemen diharapkan mempertimbangkan bagaimana cara menampilkan item ini agar dapat dikenal oleh pelanggan. Sebuah menu yang dikategorikan sebagai menu puzzle apabila contribution margin menu tersebut lebih 
rendah daripada average contribution marginnya dan menu mix percentage-nya lebih kecil daripada popularity index.

Sedangkan menu dalam kategori Dog berarti menu tersebut tidak populer dan tidak memberikan keuntungan yang berarti. Produk ini mungkin harus di hilangkan atau diberi kenaikan harga sehingga status produk ini bisa mencapai posisi puzzle. Sebuah menu yang dikategorikan sebagai dog apabila тепи mix percentage-nya lebih kecil daripada popularity index dan contribution margin тепи tersebut lebih rendah daripada average contribution margin-nya.

Berdasarkan hasil analisa mепи engineering tersebut dan dipadukan dengan mепи cycle praktikum patiseri sebelumnya. Menu dalam kategori Star akan dimasukkan dalam menu dessert prioritas pertama dan menu dalam kategori plowhorse akan dimasukkan dalam menu dessert prioritas kedua. Paket menu dalam tiap praktikum terdiri dari satu jenis roti dan satu jenis dessert (makanan penutup), oleh karenanya menu dessert prioritas pertama dan kedua merupakan menu pilihan dalam tiap praktikum. Dibawah ini paket menu cycle praktikum patiseri di Program Studi Tata Boga Politeknik Negeri Balikpapan dari hasil analisa menu engieering menu patiseri di Hotel Grand Jatra Balikpapan yaitu sebagai berikut:

Tabel 2. Menu Cycle Praktikum Patiseri Prodi Tata Boga Politeknik Negeri Balikpapan

\begin{tabular}{|c|c|c|c|}
\hline $\begin{array}{l}\text { PRAKTI } \\
\text { KUM KE }\end{array}$ & $\begin{array}{l}\text { WELCOME } \\
\text { BREAD }\end{array}$ & $\begin{array}{c}\text { DESSERT } \\
\text { PRIORITAS I }\end{array}$ & $\begin{array}{c}\text { DESSERT } \\
\text { PRIORITAS II }\end{array}$ \\
\hline 1 & Dinner Roll & Fruit cake & $\begin{array}{l}\text { Cream Caramel } \\
\text { (Pudding) }\end{array}$ \\
\hline 2 & Brioche & Fruit tartalet & $\begin{array}{c}\text { Éclair } \\
\text { (Choux Pastry) }\end{array}$ \\
\hline 3 & $\begin{array}{l}\text { Hot Cross } \\
\text { Buns }\end{array}$ & Brownies & $\begin{array}{l}\text { Brownies } \\
\text { cheese cake }\end{array}$ \\
\hline 4 & Hard Roll & Black Forest & Mocca cake \\
\hline 5 & $\begin{array}{c}\text { Beugel } \\
\text { Cinnamon \& } \\
\text { Brown Sugar }\end{array}$ & Rainbow cake & $\begin{array}{l}\text { Chocolate } \\
\text { Muffin } \\
\text { (Muffin) }\end{array}$ \\
\hline 6 & $\begin{array}{c}\text { Baguette } \\
\text { (garlic bread) }\end{array}$ & Opera cake & Red velvet cake \\
\hline
\end{tabular}

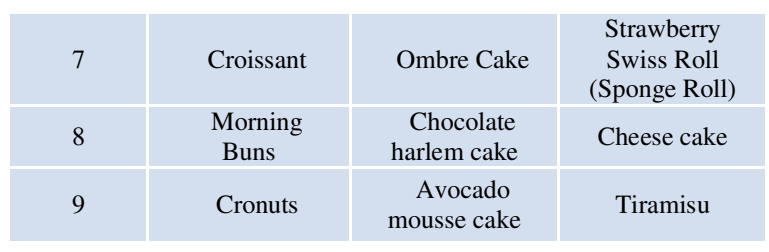

\section{Kesimpulan}

- Summary menu mix analysis dan four box analysis pada kelompok patiseri whole cake yaitu: 1) menu dalam kategori Star yaitu ombre cake, rainbow cake, dan fruit cake; 2) menu dalam kategori Plowhorse yaitu brownies cheese cake, red velvet, opera cake, cheese cake, tiramisu, chocolate harlem, mocca cake; 3) menu dalam kategori Puzzle yaitu black forest, chocolate cake, vanilla cake, lapis surabaya; 4) menu dalam kategori Dog yaitu oreo coffee ice cream, hungarian cake, dan chocolate cheese delight.

- Summary menu mix analysis dan four box analysis pada kelompok patiseri slice cake yaitu 1) menu dalam kategori Star yaitu avocado mouse cake, fruit tartalete, black forest, brownies, chocolate harlem, opera cake; 2) menu dalam kategori Plowhorse yaitu tiramisu, cheese cake, red velvet, rainbow; 3) menu dalam kategori Puzzle yaitu hungarian, chocolate merquise, chocolate cake, apple cramble, mocca cake; 4) menu dalam kategori Dog yaitu brownies cheese cake dan key lime.

- Hasil rekomendasi analisa menu engineering patiseri di Hotel Grand Jatra Balikpapan dalam penetapan menu cycle patiseri di Program Studi Tata Boga Politeknik Negeri Balikpapan yaitu diantaranya 1) Ombre Cake, 2) rainbow cake, 3) fruit cake, 4) brownies cheese cake, 5) red velvet cake, 6) opera cake, 7) cheese cake, 8) tiramisu, 9) chocolate harlem, 10) mocca cake, 11) avocado mouse cake, 12) fruit tartalete, 13) black forest, 14) brownies. 


\section{Ucapan Terima Kasih}

Ucapan terimakasih ditujukan kepada pihak Hotel Grand Jatra Balikpapan yang telah memfasilitasi dalam pengumpulan data penelitian dan pihak Dikti yang telah mendanai penelitian ini.

\section{Daftar Pustaka}

Faridah, Anni, 2008, "BSE Patiseri Jilid I", Direktorat Pembinaan Sekolah Menengah Kejuruan, Direktorat Jenderal Manajemen Pendidikan Dasar dan Menengah, Departemen Pendidikan Nasional, Jakarta.

Investor, 2013, "Momentum Emas Industri Pariwisata", Diambil pada tanggal 2 Desember 2013, dari http://www.investor.co.id/home/momentumemas-industri-pariwisata-indonesia/63175.
Kassavana, Michael L., 1999, "Computer Systems for Foodservice Opretaions A CBI Book", Van Nostrand Reinhold Company, Michigan.

LeBruto, Stephen M.; Quain, William J.; and Ashley, Robert A., 199, "Menu Engineering: A Model Including Labor", Hospitality Review: Vol. 13: Iss. 1, Article 5.

Schwatrz, Bill., 2006, "Menu Engineering: A Scientific Approach to Improved Menu Profitability", Food and Beverage Article.

Sugiyono, 2013, "Metode Peneletian Pendidikan: Pendekatan Kuantitatif, Kualitatif, dan R\&D”, Alfabeta, Bandung.

Wirartha, I Made, 2006, "Metodologi Penelitian Sosial Ekonomi”, Andi Offset, Yogyakarta. 